\title{
NHS charges are masking cuts and driving patients to GPs
}

NHS charges are driving patients with dental problems to overstretched GPs, and could soon overtake government funding as the principal source of revenue for NHS dentistry, according to new analysis from the British Dental Association (BDA).

Patient charges were first introduced in 1951 to lower demand for NHS dental services. The BDA has dubbed the charges a 'tax on health', that mask real cuts in the service and discourage the patients most in need of care.

Nearly 1 in 5 patients have delayed treatment for reasons of cost according to official statistics.

Recent academic studies show 600,000 patients, over 11,000 a week, are choosing to head to their GPs, who are not subject to

England now leads the field for basic treatment charges, with a $£ 19.70$ charge for an examination, compared to $£ 13.50$ in Wales. In Scotland check-ups are free of charge, with $£ 4.72$ for X-rays, $£ 6.76$ for extraction of one tooth or $£ 10.76$ for simple gum treatment. In Northern Ireland examinations charges start at $£ 6.68$.

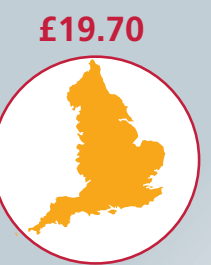

$£ 13.50$

$\mathbf{f 0 . 0 0}$

$\mathbf{f 6 . 6 8}$
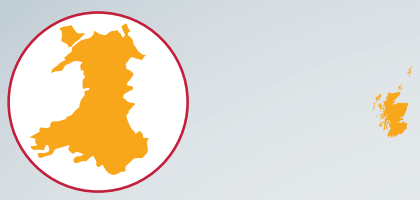

Many patients on low to moderate incomes are offered no exemptions from these charges by government.

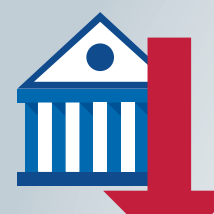

f170 million
Direct government investment in the service in England has fallen by $£ 170$ million since 2010, while the gross budget has been topped up by inflated patient charges. The BDA has estimated a likely continuation of the $5 \%$ uplift in in patient charge income, alongside a $1 \%$ annual increase in the gross budget (comprised of both patient charges and direct government spending). Based on current trends, patient charges in England are on course to contribute one third of the total dental budget within the next four years - and on track to exceed funding from government by $2031 / 32$.
The last Adult Dental Health Survey reports

$f_{f} f \quad$ that just over a quarter of of dental treatment they opted for has been affected by cost

\section{$f_{f_{f}} \quad$ and almost one-fifth (19\%) say that they had delayed dental treatment for the} same reason $f_{f} f$ adults (26\%) say that the type

\begin{abstract}
Patients in England are expected to pay a far greater share of the budget than those in all other devolved nations. The share of the NHS dental budget paid by patients through charges has risen from $18.6 \%$ in 2006 to $26.1 \%$ in 2015 in England, while in Scotland it has fallen from $26.3 \%$ to just $16.9 \%$.
\end{abstract}

The future of the patient charge in England

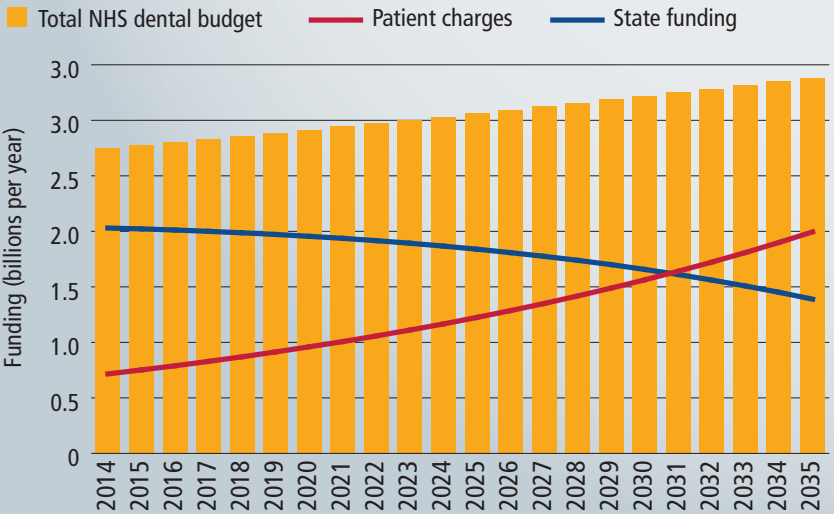

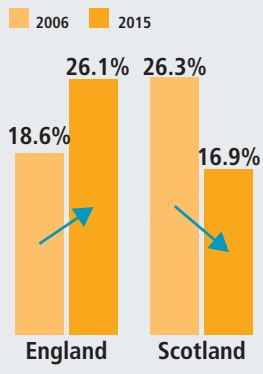

4 nations -2 approaches: Patient charge revenue in devolved nations England Wales $\longrightarrow$ Scotland N. Ireland UK 30.0

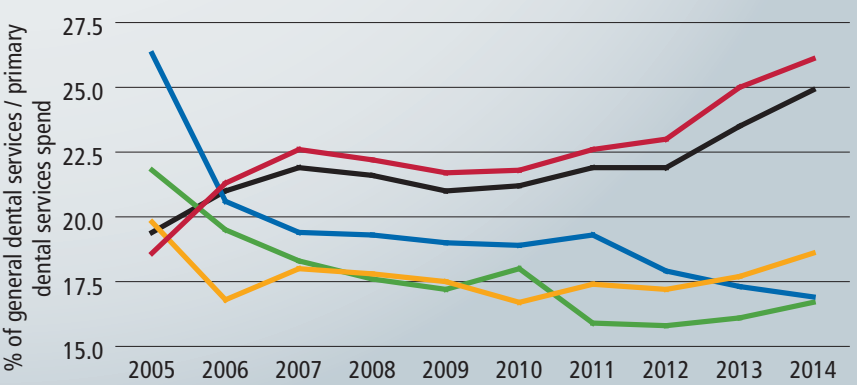


$\varangle$ nations - whose systems have become less reliant on charge income over the last decade. The $\mathrm{BDA}$ is now sending information posters to over $8,000 \mathrm{NHS}$ dentists across England to help canvas feedback from patients on the future of the charge.

The BDA's General Dental Practice chair, Henrik Overgaard-Nielsen, said: 'Ministers insist the NHS will remain free at the point of use, but keep ramping up England's dental charges. Increasingly they look like a tax on health, a substitute for adequate government investment which drives down demand from the patients who need us most. These increases aren't putting an extra penny into the service, they are just a winning formula for cuts by stealth.

'We're told our patients should make a "contribution" toward the cost of NHS dentistry. Well unless ministers change course, our patients will end up paying more into the service than the state within a generation. The term "NHS dentistry" ceases to have much meaning if patients are expected to pay the lion's share of their treatment costs at the point of delivery'.

\section{UCLH staff get tough and muddy for charity}

A group of 11 staff from Eastman Dental Hospital and the Royal National Throat, Nose and Ear Hospital (both UCLH) have raised over $£ 3,000$ to improve patient care for hypodontia and ectodermal dysplasia (ED) patients.

The team battled through 11 gruelling miles of mud and obstacles in the 'Tough Mudder' event to raise the funds. It was also used as a team building experience with staff from a wide variety of specialities and grades/roles participating.

Approximately 3-6\% of the population will be affected by hypodontia with one in 1,400 affected by ED. The treatment requires a multidisciplinary approach often requiring orthodontic, paediatric dentistry, oral surgery, restorative and periodontology input to reach satisfactory outcomes.

The funds, which are still coming in, should improve the facilities for this specific patient group.

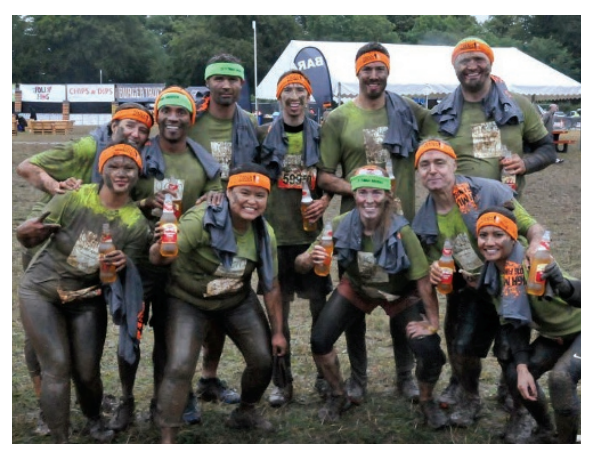

Miss Carolyn Whyte of the Eastman said: 'Completing the Tough Mudder as a UCLH team pushed everyone out of their comfort zones and fostered inter-hospital and inter-departmental team spirit. The event was a huge success with all team members completing the challenge with smiles to the very end. Many aches, scrapes and pains were endured but the team already have plans for another fundraising event early next year!' 